\title{
Penerapan Payment Gateway pada Aplikasi Marketplace Waroeng Mahasiswa Menggunakan Midtrans
}

\author{
Alfian$^{1}$, Petrus Sokibi ${ }^{2}$, Lena Magdalena ${ }^{3}$ \\ Program Studi Teknik Informatika, Universitas Catur Insan Cendekia, \\ Jl. Kesambi No. 202 Kota Cirebon, Indonesia, 45134 \\ e-mail: ${ }^{1}$ alfianrenz25@gmail.com, ${ }^{2}$ petrussokibi@gmail.com, ${ }^{3}$ lena.magdalena@cic.ac.id
}

Submitted Date: September $03^{\text {rd }}, 2020$

Revised Date: September 22nd, 2020
Reviewed Date: September 22 $2^{\text {nd }}, 2020$

Accepted Date: September $30^{\text {th }}, 2020$

\begin{abstract}
Catur Insan Cendekia University is one of the universities in Cirebon City which is based on technology and management. As an educational institution that has a technopreneur campus slogan, many Catur Insan Cendekia University students have implemented entrepreneurship courses and have developed into new entrepreneurial owners scattered on various social media. However, due to limited space and marketing reach in the campus area, many academicians do not see the product / service offerings made by Catur Insan Cendekia University students. So a work program called Waroeng Mahasiswa was launched by BKM CIC with the aim of being a space for students to market their products / services in the Catur Insan Cendekia University campus area. The Waroeng Mahasiswa work program will be developed into a web-based marketplace application made using the PHP programming language. This marketplace application will also be equipped with an online payment system that is integrated with Midtrans as a payment gateway service provider to make the transaction process faster, easier and more practical.
\end{abstract}

Keywords: Marketplace Application; Waroeng Mahasiswa; Payment Gateway; Midtrans

\section{Abstrak}

Universitas Catur Insan Cendekia merupakan perguruan tinggi di Kota Cirebon yang berbasis teknologi dan manajemen. Sebagai lembaga pendidikan yang memiliki slogan kampus technopreneur, banyak mahasiswa Universitas Catur Insan Cendekia yang mengimplementasikan pembelajaran mata kuliah kewirausahaan dan berkembang menjadi pemilik wirausaha pemula yang bertebaran di berbagai media sosial. Namun karena keterbatasan ruang dan jangkauan pemasaran diarea kampus, banyak sivitas akademika yang tidak mengetahui penawaran produk/jasa yang dilakukan oleh mahasiswa Universitas Catur Insan Cendekia. Maka diusunglah sebuah program kerja bernama Waroeng Mahasiswa yang dicanangkan oleh BKM CIC dengan tujuan sebagai ruang bagi mahasiswa untuk memasarkan produk/jasanya di area kampus Universitas Catur Insan Cendekia. Program kerja Waroeng Mahasiswa akan dikembangkan menjadi sebuah aplikasi marketplace berbasis web yang dibuat dengan menggunakan bahasa pemrograman PHP. Aplikasi marketplace ini akan dilengkapi dengan sistem pembayaran online yang terintegrasi dengan Midtrans sebagai penyedia jasa payment gateway agar proses transaksi menjadi lebih cepat, mudah dan praktis.

Kata Kunci: Aplikasi Markeptlace; Waroeng Mahasiswa; Payment Gateway; Midtrans

\section{Pendahuluan}

Saat ini, aktivitas berbelanja secara online menjadi kegiatan yang lazim dilakukan oleh banyak orang. Hal ini tentunya tidak lepas dari adanya peran marketplace. Marketplace merupakan sebuah pasar virtual di mana pasar tersebut menjadi tempat bertemunya pembeli dengan penjual untuk melakukan transaksi. Marketplace mempunyai fungsi yang sama dengan pasar tradisional, perbedaannya adalah marketplace lebih terkomputerisasi dengan menggunakan bantuan sebuah jaringan dalam mendukung sebuah pasar agar dapat menyediakan update informasi dan layanan jasa untuk penjual 
dan pembeli yang berbeda-beda (Betti Dame Hutauruk, Jimmy Febrianus Naibaho, 2017). Sebagai contoh marketplace yang sudah ada di tengah masyarakat Indonesia saat ini yaitu Tokopedia, Bukalapak, Shopee, Lazada, dan Elevenia (Artaya \& Purworusmiardi, 2019).

Universitas Catur Insan Cendekia (UCIC) merupakan perguruan tinggi yang terletak di Kota Cirebon dan merupakan perguruan tinggi yang menyediakan layanan jasa pendidikan di bidang komputer dan manajemen. Universitas Catur Insan Cendekia mengusung mahasiswanya untuk dapat memiliki jiwa technopreneurship, mengacu pada pembelajaran di area perkuliahan agar kedepannya mahasiswa bisa memanfaatkan teknologi untuk membuka lapangan pekerjaan dan menjadi wirausaha yang dapat mengikuti arus perkembangan zaman. Untuk memberikan ilmu sekaligus kemampuan yang seimbang menuju mahasiswa yang memiliki jiwa technopreneurship, Universitas Catur Insan Cendekia memberikan mata kuliah Kewirausahaan untuk seluruh mahasiswa. Dalam pembelajarannya, selain memberikan teori wirausaha, mahasiswa juga diajak untuk merealisasikan beberapa pembelajarannya seperti membuat rancangan atau proposal sebuah usaha, membuat dan memasarkan produk/jasa tersebut yang kemudian hasilnya dibuat laporan dan dipresentasikan di hadapan mahasiswa lain. Namun karena keterbatasan ruang dan jangkauan pemasaran diarea kampus, banyak sivitas akademika yang tidak mengetahui penawaran produk/jasa yang dilakukan oleh mahasiswa Universitas Catur Insan Cendekia. Maka diusunglah program kerja bernama Waroeng Mahasiswa yang dicanangkan oleh BKM CIC dengan tujuan sebagai ruang bagi mahasiswa Universitas Catur Insan Cendekia untuk memasarkan produk/jasanya di area kampus. Program kerja Waroeng Mahasiswa akan dikembangkan menjadi sebuah aplikasi marketplace berbasis web yang dibuat dengan menggunakan bahasa pemrograman PHP dikombinasikan dengan Framework CodeIgniter. Adanya aplikasi marketplace dapat menjadi ruang khusus bagi mahasiswa Universitas Catur Insan Cendekia untuk memasarkan produk/jasanya dengan mudah. Marketplace ini dapat menjadi sebuah pasar yang mempertemukan mahasiswa sebagai penjual dengan pembeli baik dari internal maupun eksternal kampus Universitas Catur Insan Cendekia.

Penelitian mengenai pembuatan aplikasi marketplace pernah dilakukan sebelumnya, di mana dari penelitian tersebut membahas tentang produk kewirausahaan mahasiswa Universitas PGRI Yogyakarta (UPY) yang masih menggunakan cara konvensional dalam memasarkan produknya. Maka dibuatlah aplikasi marketplace yang dapat memasarkan produk kewirausahaan mahasiswa UPY secara online. Namun dari penelitian tersebut, kegunaan marketplace hanya sebatas media untuk memasarkan produk saja dan tidak dilengkapi dengan sistem pembayaran (Wahana, 2018).

Dari kekurangan yang ada pada penelitian sebelumnya, sistem pembayaran sangat perlu diterapkan pada aplikasi marketplace. Maka dari itu, penulis tertarik menerapkan sistem pembayaran dengan payment gateway menggunakan Midtrans (Puspitasari \& Maulina, 2019). Midtrans adalah payment gateway yang memiliki fitur untuk mempermudah melakukan pengujian pembayaran (Febriyanto et al., 2019). Secara teori, payment gateway bertindak sebagai jembatan antara pemilik website dengan institusi keuangan dalam melakukan proses transaksi (Islami \& Sulistyowati, 2016). Dengan adanya payment gateway, pembeli dapat melakukan pembayaran secara online sehingga proses transaksi menjadi lebih cepat, mudah dan praktis.

\section{Landasan Teori}

Beberapa yang menjadi landasan teori adalah sebagai berikut:

\section{a. Aplikasi}

Aplikasi merupakan penerapan, menyimpan sesuatu hal, data, permasalahan, pekerjaan ke dalam suatu sarana atau media yang dapat digunakan untuk diterapkan menjadi sebuah bentuk yang baru. Pengertian aplikasi secara umum adalah alat terapan yang difungsikan secara khusus dan terpadu sesuai kemampuan yang dimilikinya aplikasi merupakan suatu perangkat komputer yang siap pakai bagi user (Siregar \& Melani, 2019).

\section{b. E-Commerce}

E-commerce adalah suatu proses membeli dan menjual produk-produk secara elektronik oleh konsumen dan dari perusahaan ke perusahaan dengan komputer sebagai perantara transaksi bisnis. Keberadaan e-commerce sendiri dalam internet dapat dikenali melalui adanya fasilitas pemasangan iklan, penjualan, dan service support terbaik bagi seluruh pelanggannya dengan menggunakan sebuah toko online berbentuk web yang setiap harinya beroperasi 24 jam (Meriyanti \& Safriadi, 2016). 


\section{c. Marketplace}

Marketplace merupakan sebuah pasar virtual di mana pasar tersebut menjadi tempat bertemunya pembeli dan penjual untuk melakukan transaksi. (Hutauruk, Naibaho \& Rumahorbo, 2017). EMarketplace merupakan lokasi online di mana pembeli dan penjual melakukan transaksi komersial seperti menjual barang, jasa atau informasi (Putra et al., 2017).

\section{d. Payment Gateway}

Payment gateway adalah pembayaran online yang fungsinya mendeskripsikan dan mengesahkan informasi pada sebuah transaksi sesuai dengan kebijakan yang telah diatur oleh para provider. (Kurniawan et al., 2018).

\section{e. Midtrans}

Midtrans adalah salah satu payment gateway yang memfasilitasi kebutuhan para pebisnis online dengan memberikan pelayanan dengan berbagai metode pembayaran. Pelayanan tersebut memungkinkan para pelaku industri lebih mudah beroperasi dan meningkatkan penjualan (Febriyanto et al., 2019).

\section{Metodologi Penelitian} adalah:

Metode yang digunakan dalam penelitian ini

\section{a. Metode Pengumpulan Data}

Metode pengumpulan data yang dilakukan antara lain:

1. Observasi,

Kegiatan yang dilakukan pada tahap ini adalah mengumpulkan data profil Universitas Catur Insan Cendikia dan Badan Koordinasi Mahasiswa CIC seperti sejarah, visi, misi dan tujuan, serta data Mahasiswa Universitas Catur Insan Cendekia.

2. Wawancara

Wawancara dilakukan dengan cara menyampaikan sejumlah pertanyaan dari pewawancara kepada narasumber. Kegiatan ini dilakukan untuk mendapatkan data melalui tanya jawab secara langsung dengan Badan Koordinasi Mahasiswa CIC dan Mahasiswa Universitas Catur Insan Cendekia.

\section{Studi Literatur}

Kegiatan yang dilakukan pada tahap ini adalah membaca dan mempelajari literatur dari berbagai sumber, jurnal ilmiah, buku referensi, dokumentasi kampus yang berkaitan dengan penelitian, internet, dan pustaka lainnya yang berkaitan dengan topik penelitian yang diambil.

\section{b. Metode Pengembangan Perangkat Lunak}

Dalam pengembangan perangkat lunak, penelitian ini menggunakan metode waterfall yaitu sebuah metode pengembangan software yang bersifat sekuensial dan terdiri dari lima tahap yang saling terkait dan mempengaruhi seperti terlihat pada gambar berikut:

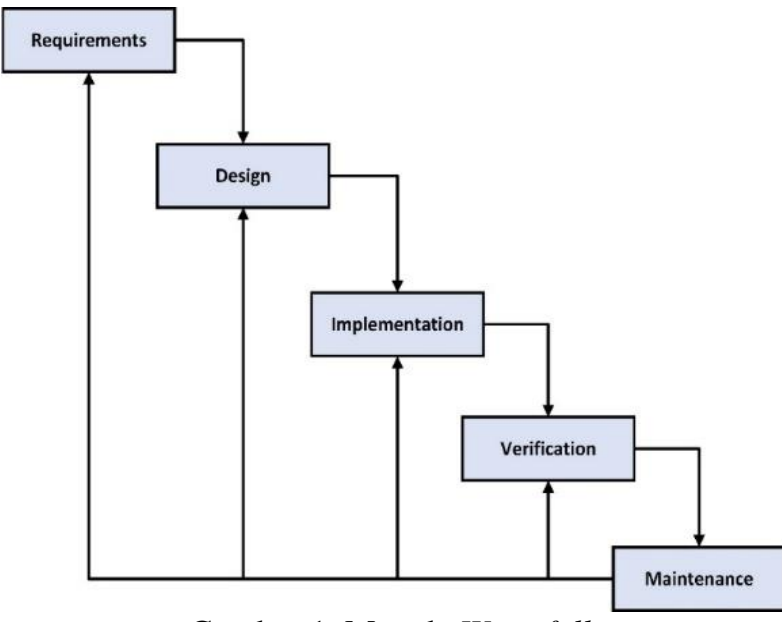

Gambar 1. Metode Waterfall

Tahapan pengembangan perangkat lunak berdasarkan Gambar 1 adalah:

1. Requirements (Analisa Kebutuhan Sistem)

Pada tahap ini, penulis melakukan pengumpulan data melalui observasi dan wawancara langsung mengenai masalah yang sering dialami oleh mahasiswa Universitas Catur Insan Cendekia yang memiliki usaha dibidang produk atau jasa.

2. Design (Desain)

Tahap selanjutnya yaitu proses desain di mana penulis merancang serta menentukan alur sistem secara keseluruhan dengan menggunakan UML (Unified Modelling Language)

3. Implementation (Implementasi)

Berikutnya adalah tahap implementasi, di mana penulis menerjemahkan keseluruhan desain sistem yang telah disusun menjadi kodekode program sehingga dihasilkan sistem secara keseluruhan.

4. Verification (Verifikasi)

Pada tahap verifikasi, sistem yang sudah dibuat akan di test untuk menguji apakah sistem tersebut telah berfungsi dengan baik sesuai dengan tahap analisis dan desain yang telah dilakukan. 


\section{Maintenance (Perawatan)}

Tahap akhir adalah perawatan, di mana penulis melakukan pemeliharaan sistem termasuk diantaranya instalasi dan proses perbaikan sistem apabila ditemukan adanya kesalahan/bug yang tidak ditemukan pada tahap verifikasi.

\section{Analisis dan Implementasi}

\section{a. Analisis Kebutuhan Fungsional}

Kebutuhan fungsional adalah kebutuhan yang berisi proses-proses atau layanan apa saja yang nantinya harus disediakan oleh sistem, mencakup bagaimana sistem harus bereaksi pada input tertentu dan bagaimana perilaku sistem pada situasi tertentu. Berikut ini adalah kebutuhan fungsional pada aplikasi marketplace Waroeng Mahasiswa:

1. Sistem dapat memvalidasi username dan password ketika Login.

2. Sistem dapat menampilkan informasi kepada pengguna apabila terjadi kesalahan dalam pengisian form.

3. Sistem dapat menampilkan halaman menu sesuai dengan level pengguna.

4. Sistem dapat menambah, mengubah dan menghapus data.

5. Sistem dapat menampilkan, mengunggah, mengubah dan menghapus gambar.

6. Sistem dapat menampilkan data produk dan data penjual pada halaman utama marketplace.

7. Sistem dapat mengintegrasikan Google Mail untuk verifikasi akun pengguna dan notifikasi pembayaran.

8. Sistem dapat mengintegrasikan Midtrans sebagai penyedia layanan jasa payment gateway.

9. Sistem dapat menambahkan produk kedalam keranjang belanja.

10.Sistem dapat menampilkan pilihan metode pembayaran yang terintegrasi dengan Midtrans.

11. Sistem dapat menampilkan status pembayaran dan status pesanan kepada penjual maupun pembeli.

\section{b. Analisis Kebutuhan Non-Fungsional}

Kebutuhan non-fungsional adalah kebutuhan yang menunjukkan atribut mutu, batasan implementasi, performa sistem, usability, hingga antarmuka yang harus dimiliki software atau sistem. Berikut ini adalah kebutuhan nonfungsional pada aplikasi marketplace Waroeng Mahasiswa:

1. Sistem dapat diakses diberbagai perangkat seperti smartphone, tablet, komputer dan laptop menggunakan browser.
2. Sistem tidak menyediakan fitur cek ongkos pengiriman berdasarkan jarak.

3. Sistem tidak menyediakan fitur pelacakan pengiriman barang.

4. Batas waktu pembayaran yaitu 1 kali 24 jam.

c. Mekanisme Pembelian Pada Aplikasi Marketplace Waroeng Mahasiswa

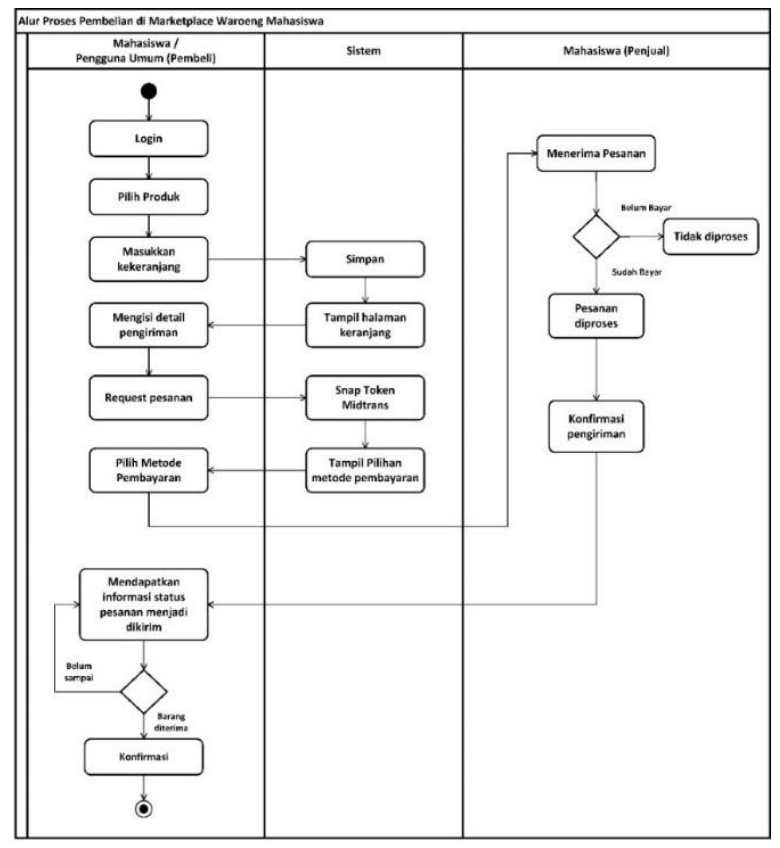

Gambar 2. Mekanisme Pembelian

Keterangan Gambar 2:

1. Dimulai dari aktor mahasiswa yang berstatus sebagai pembeli dengan melakukan login.

2. Setelah login mahasiswa harus memilih produk yang akan dibeli dan memasukkannya kedalam keranjang.

3. Kemudian sistem akan menyimpan produk yang dipilih oleh mahasiswa kedalam database dan menampilkan halaman keranjang.

4. Setelah mengelola produk yang ada pada keranjang, mahasiswa dapat memesan produk yang ada pada keranjang dan mengisi detail pengiriman.

5. Sistem akan terhubung ke Midtrans dan menampilkan pilihan metode pembayaran. Pada bagian ini, mahasiswa dapat memilih metode pembayaran yang dinginkan.

6. Mahasiswa yang berstatus sebagai penjual akan mendapatkan notifikasi pesanan masuk. Kemudian penjual dapat memproses pesanan apabila customer telah melakukan pembayaran.

7. Setelah itu, penjual dapat mengkonfirmasi pengiriman kepada pembeli dan pada saat itu 
juga status pesanan yang ada pada halaman penjual dan pembeli berubah menjadi dikirim.

8. Tahap terakhir, mahasiswa wajib mengkonfirmasi kepada penjual apabila produk telah diterima.

\section{d. Perancangan Sistem}

1. Use Case Diagram BKM CIC (Administrator)

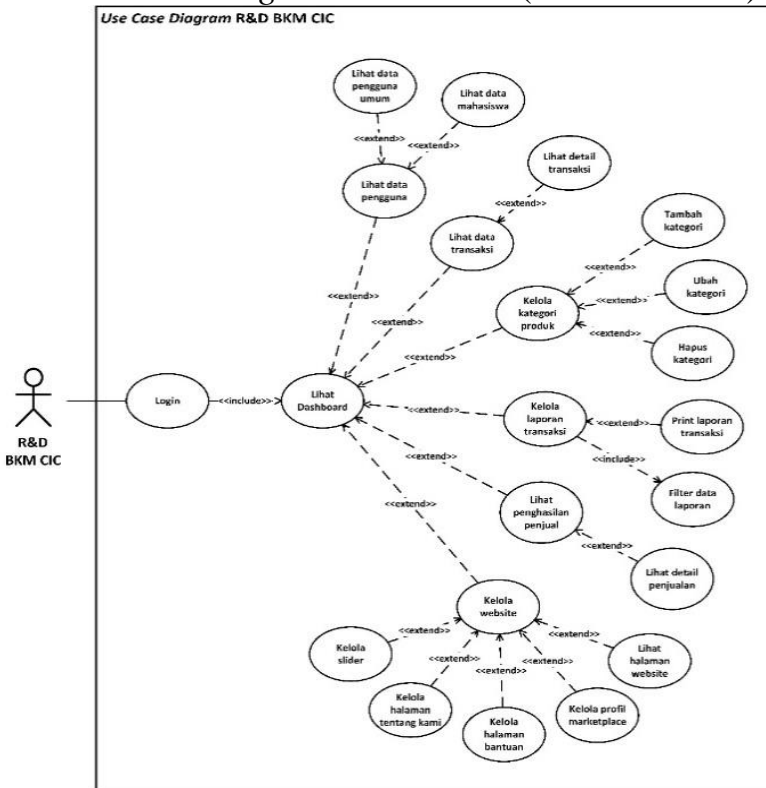

Gambar 3. Use Case Diagram BKM CIC

2. Use Case Diagram Mahasiswa (Penjual dan Pembeli)

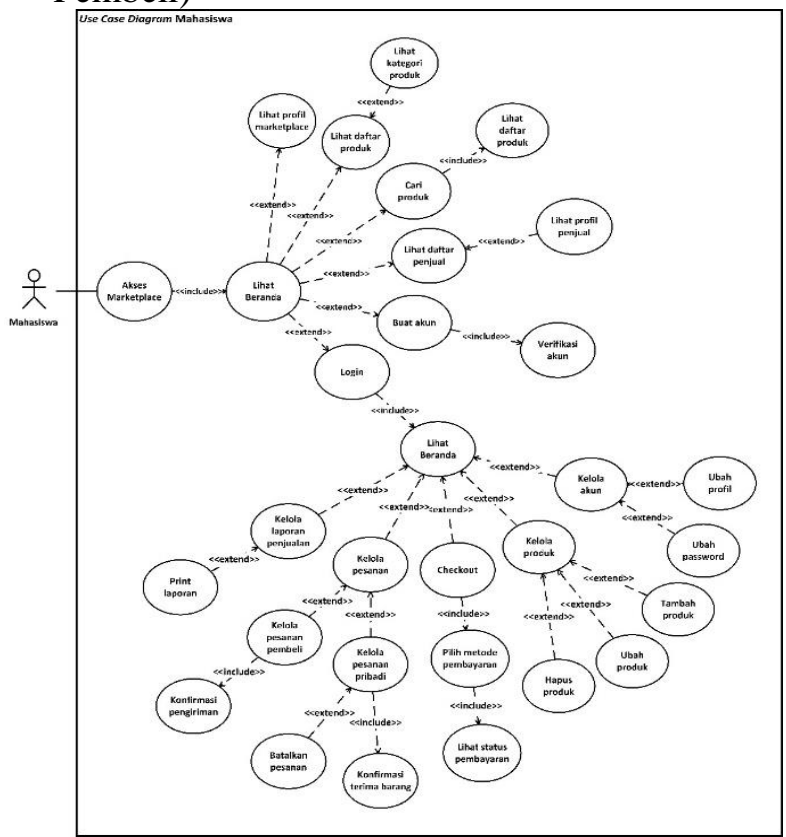

Gambar 4. Use Case Diagram Mahasiswa
3. Activity Diagram Checkout

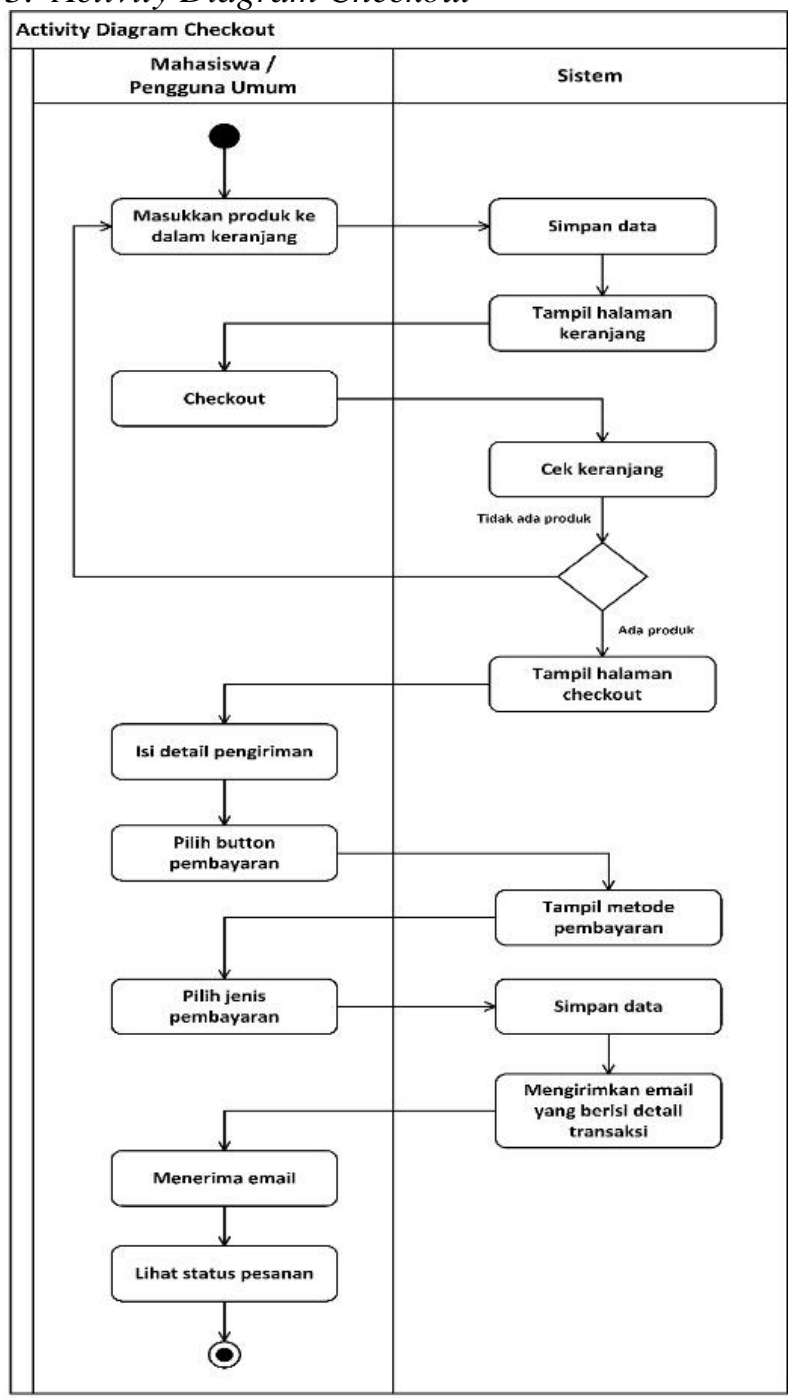

Gambar 5. Activity Diagram Checkout

\section{e. Implementasi}

1. Halaman Buat Akun Mahasiswa

Halaman buat akun digunakan oleh mahasiswa untuk membuat akun pada aplikasi marketplace Waroeng Mahasiswa dengan cara mengisi form registrasi yang terdapat pada halaman tersebut. 


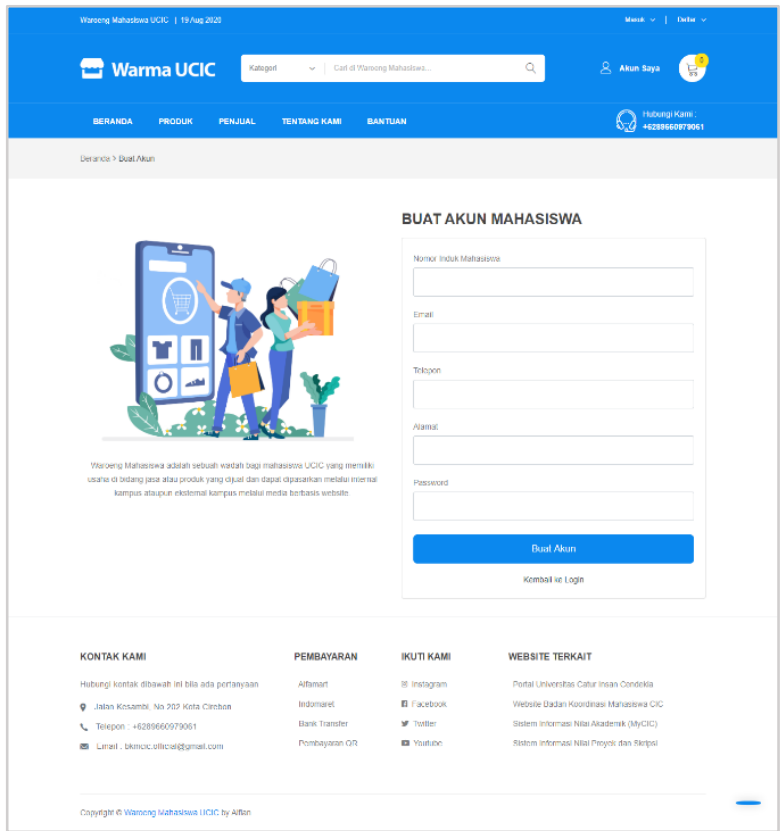

Gambar 6. Halaman Buat Akun Mahasiswa

\section{Halaman Utama Marketplace}

Halaman utama marketplace merupakan halaman yang pertama kali tampil ketika pengguna berhasil mengakses website marketplace. Pada halaman ini terdapat beberapa menu yaitu menu produk, penjual, tentang WarMa dan bantuan.

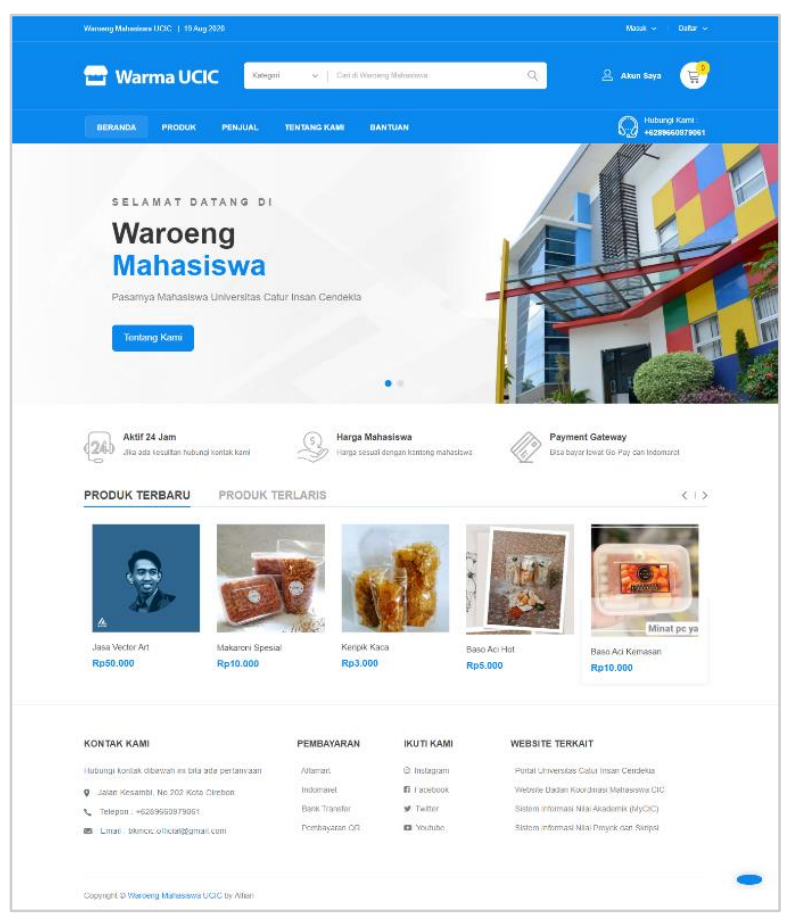

Gambar 7. Halaman Utama Marketplace

\section{Halaman Menu Produk}

Halaman menu produk berfungsi untuk menampilkan data produk yang dijual oleh mahasiswa Universitas Catur Insan Cendekia.

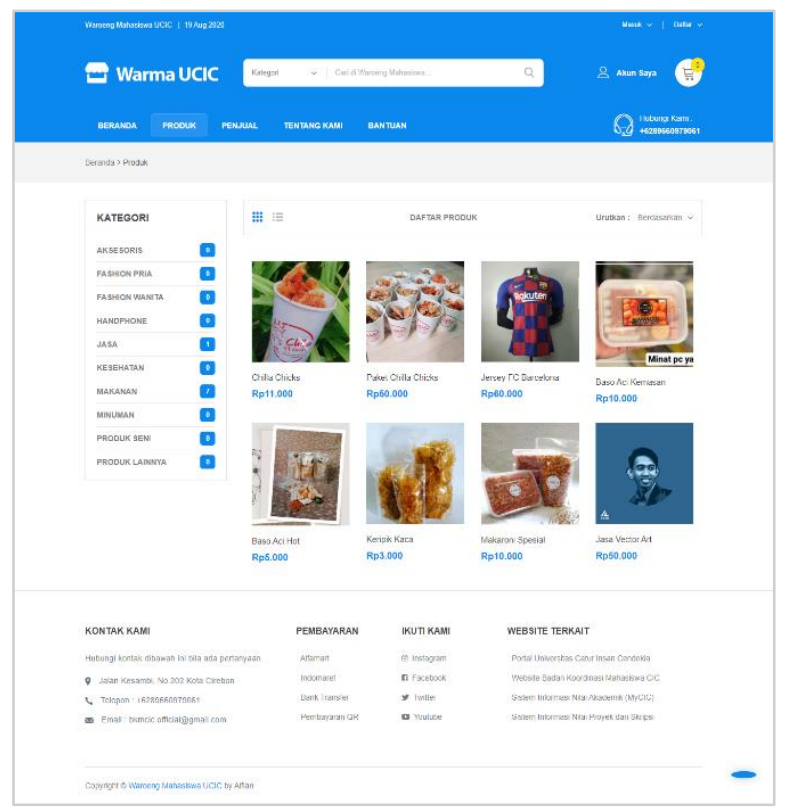

Gambar 8. Halaman Menu Produk

\section{Halaman Dashboard Midtrans}

Halaman dashboard Midtrans merupakan halaman yang digunakan oleh BKM CIC untuk mengetahui transaksi pembayaran yang masuk

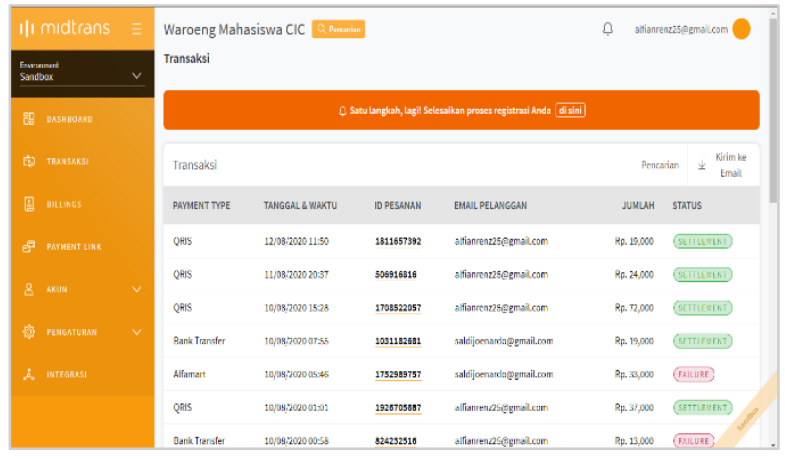

Gambar 9. Halaman Dashboard Midtrans

\section{Halaman Pembayaran}

Halaman pembayaran tampil apabila pembeli telah mengisi detail pengiriman yang ada pada halaman checkout. Kemudian sistem akan menampilan pop-up pilihan pembayaran yang terintegrasi dengan Midtrans. 


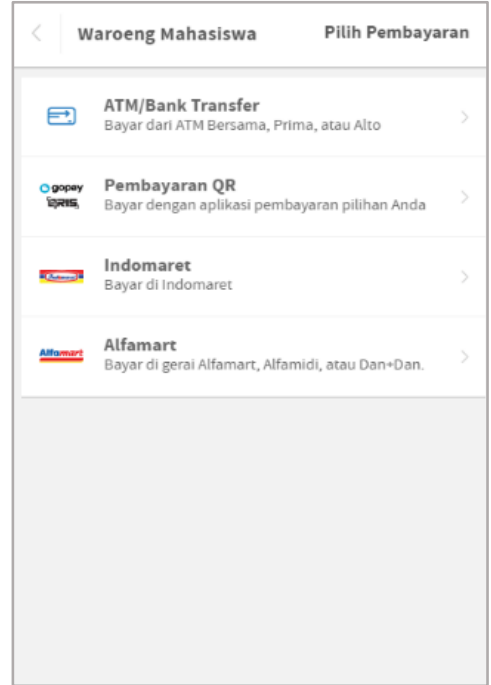

Gambar 10. Halaman Pilihan Metode Pembayaran

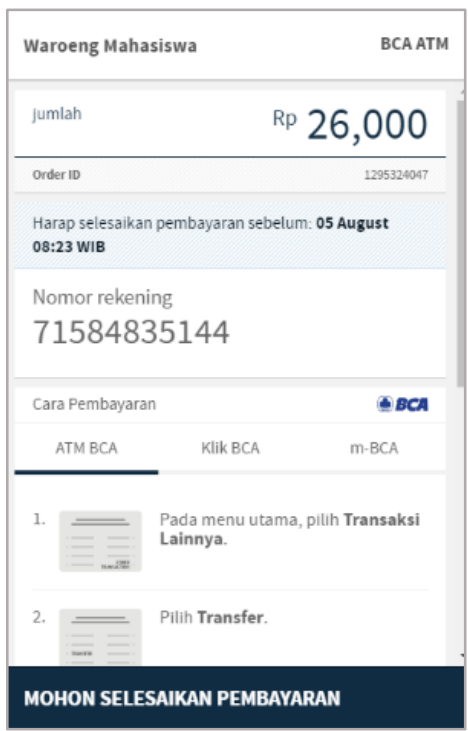

Gambar 11. Halaman Pembayaran Menggunakan Virtual Account

\section{Kesimpulan}

Berdasarkan hasil implementasi pada aplikasi marketplace Waroeng Mahasiswa dengan sistem pembayaran berbasis payment gateway, maka penulis dapat menyimpulkan sebagai berikut:

1. Aplikasi marketplace ini dapat dimanfaatkan sebagai ruang khusus bagi mahasiswa Universitas Catur Insan Cendekia untuk memasarkan produk/jasa yang ditawarkannya kepada internal maupun eksternal kampus Universitas Catur Insan Cendekia melalui media berbasis website.

2. Hasil dari aplikasi marketplace ini dapat menyediakan informasi bagi sivitas akademika Universitas Catur Insan Cendekia dalam mengetahui produk/jasa apa saja yang ditawarkan oleh mahasiswa. Oleh sebab itu aplikasi ini dapat menjangkau pemasaran usaha mahasiswa yang semakin luas atas produk/jasa yang ditawarkan, dengan harapan pemasaran tersebut dapat berjalan maksimal.

3. Penerapan sistem pembayaran dengan payment gateway dapat memudahkan pembeli dan penjual dalam melakukan transaksi. Dengan adanya sistem pembayaran online, proses transaksi menjadi lebih cepat, mudah dan praktis.

\section{Referensi}

Artaya, I. P., \& Purworusmiardi, T. (2019). Efektifitas Marketplace Dalam Meningkatkan Konsentrasi Pemasaran Dan Penjualan Produk Bagi Umkm Di Jawa Timur. Ekonomi Dan Bisnis, Universitas Narotama Surabaya, 1-10.

Febriyanto, E., Rahardja, U., \& Alnabawi, N. (2019). Penerapan Midtrans sebagai Sistem Verifikasi Pembayaran pada Website iPanda. Jurnal Informatika Upgris, 246-248.

Hutauruk, B.D., Naibaho, J.F., \& Rumahorbo, B. (2017). Analisis dan Perancangan Aplikasi Marketplace Cinderamata khas Batak Berbasis Android. Jurnal Methodika, 243-244.

Islami, D. R., \& Sulistyowati, Y. (2016). Aplikasi Penjualan Pulsa Online Menggunakan Payment Gateway. Jurnal Informatika Dan Multimedia, 4243.

Kurniawan, D., Zusrony, E., \& Kusumajaya, R. A. (2018). Analisa Persepsi Pengguna Layanan Payment Gateway Pada Financial Technology Dengan Metode Eucs. Jurnal Informa Politeknik Indonusa Surakarta, 2-3.

Meriyanti, U., \& Safriadi, N. (2016). Rancang Bangun E-Commerce Tenun Songket Sambas Sahidah. Jurnal Sistem Dan Teknologi Informassi, 1-2.

Puspitasari, T. M. M., \& Maulina, D. (2019). Implementasi Payment Gateway Menggunakan Midtrans Pada Marketplace Travnesia.Com. Mobile and Forensics, 1-10.

Putra, A. K., Nyoto, R. D., \& Sasty, P. H. (2017). Rancang Bangun Aplikasi Marketplace Penyedia Jasa Les Private Di Kota Pontianak Berbasis Web. Jurnal Sistem Dan Teknologi Informasi, 22-23.

Siregar, H. F., \& Melani, M. (2019). Perancangan Aplikasi Komik Hadist Berbasis Multimedia. Jurnal Teknologi Informasi, 113-114.

Wahana, A. (2018). Rancang Bangun Marketplace Produk Kewirausahaan Mahasiswa UPY Berbasis Content Management System. Jurnal Dinamika Informatika, 73-81. 